\title{
Cashless play in UK bingo: Two paradoxes in the use of player surveillance
} tools. $^{1}$

Professor Kate Bedford, Birmingham Law School, University of Birmingham, UK.

Email: k.bedford@bham.ac.uk

\section{Introduction}

What can bingo can add to our academic, law, and policy debates about gambling and political economy? ${ }^{2}$ I have been trying, for a while now, to make the case that bingo matters to academics - in its own right (it is a globally-significant, popular, though under-researched form of play that has historically been central to the development of gambling law and policy) - and because it offers a new lens on broader concerns about diverse economies, and the ways in which they are shaped by law. Like many other authors interested in this new journal, I spend much of my time arguing that the concerns of mainstream gambling studies are too narrow.

In this blog post, however, I want to share some thoughts about an issue that is absolutely central to mainstream gambling studies: responsible gambling (RG). In particular, I want to think about the role of cash use in responsible gambling, given the widespread claim that registered play, associated with card use, can be an effective harm reduction tool. ${ }^{3}$ In a shortened version of an argument that I make in my book, Bingo Capitalism, I suggest that critical gambling scholars need to think carefully about player tracking as a solution to excessive gambling. The short version of my argument is this: I am worried about the fact that states and academics - not just businesses - are increasingly motivated to gather, and extract value from, gambling data, and I am unconvinced that it will help matters. Because cash use helps players to limit spending, account-based play may even be counterproductive, undercutting long-established mechanisms for regulating excessive play. Specifically, I identify two paradoxes that emerge from consideration of bingo in the UK, both of which under-cut the promise of account-based play to foster responsible play: 1. the safety of cash, and 2. the additional risks posed by online play.

\footnotetext{
${ }^{1}$ This blog post is an expanded version of an argument about player tracking and cash use that I first published in Bedford 2018 (b). A longer version of the argument is contained in Bedford 2019.

${ }^{2}$ See e.g. Bedford, K. 2015; 2018. For the relevance of bingo to law and policy debates, see Bingo Project 2016. ${ }^{3}$ In other work I have explored other dimensions of cash use, including the requirement for workers (paid and unpaid) to show 'clean hands' after touching cash in B.C. bingo halls. See Bedford, K. 2018.
} 


\section{The Broader Academic and Policy Debate}

Player tracking was originally built into the design of gambling machines to increase profit. However, in many jurisdictions these player tracking technologies have been deployed as a Responsible Gambling mechanism (Schüll, 2012, p. 260). Some machines are equipped with pop-ups on play time

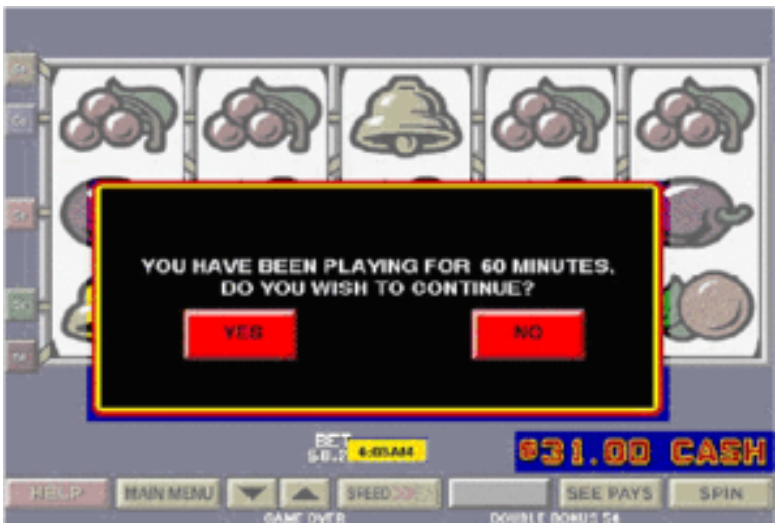

Image from https://www.basisonline.org/2 1 or tips on RG, or software that allows players to perform voluntary acts of self-governance, such as budget management tools, limits setting, selfexclusion, or personal risk evaluations (275). In other cases, play data is monitored to pick up on patterns that might indicate problem gambling, such as repeated top ups; these can be used to generate alerts that send over a member of staff, or that freeze advertising (283-4). Some credit card companies allow people to block their cards from being used to gamble (https://www.theguardian.com/society/2019/nov/15/halifax-hsbc-block-cards-from-gambling).

Increasingly, there is also hope that the metadata of online play might be used more effectively, with algorithms used to find patterns and correlations and thereby allow better policy interventions.

Some academics are very supportive of player tracking. ${ }^{4}$ However, others are more sceptical, on the grounds that surveillance technologies to monitor and shape the habits of players have a dual, and arguably inherently conflictual role: to enable more effective marketing so as to accelerate consumption, while also promising to increase safety. ${ }^{5}$

In my research on the UK bingo sector, I seek to further dampen the 'hype and hope' (Rieder \& Simon, 2016, p. 4) about how technology will resolve problematic gambling, by troubling the joint state/researcher faith in algorithms on which it rests. This faith rests on the promise that player tracking technologies will provide real-time feedback, find patterns that cannot be detected by human cognition, distil them into predictive analytics, and generate new policy solutions (van Dijck, 2014; Yeung, 2017a, 2017b). I draw instead on more critical accounts of big data that doubt the ability of algorithms to access truths about social life, and that question the desirability of subsequent measures to identify or pre-empt risk (Rieder \& Simon, 2016; Yeung, 2017a, 2017b; Scholz, 2012). One key insight from these accounts is that big data is not just of interest to companies. Data produced by consumers can also be a resource for employers, police (Andrejevic, 2012, p. 160), regulators, and academics (Boyd \& Crawford, 2012; van Dijck, 2014). For many critics, it is the 'inextricable knot' of commercial, state, and researcher interests in metadata that explains the proliferation of tracking, and associated efforts to convince the general public that continuous surveillance is in our collective interests (van Dijck 2014, p. 203).

\footnotetext{
${ }^{4}$ E.g. Gainsbury 2011; Griffiths 2014; Parke et al. 2008.

${ }^{5}$ E.g. Schüll 2012: 276. On personalized advertising as a feature of mobile gaming platforms, shaped by algorithms that learn from the time, place, and type of play, see Reith 2016.
} 
Applying these insights to gambling studies should lead us to pause in our embrace of cashless play as a SR mechanism.

Social Responsibility in UK Commercial Bingo Halls and the growing emphasis on Player Tracking.

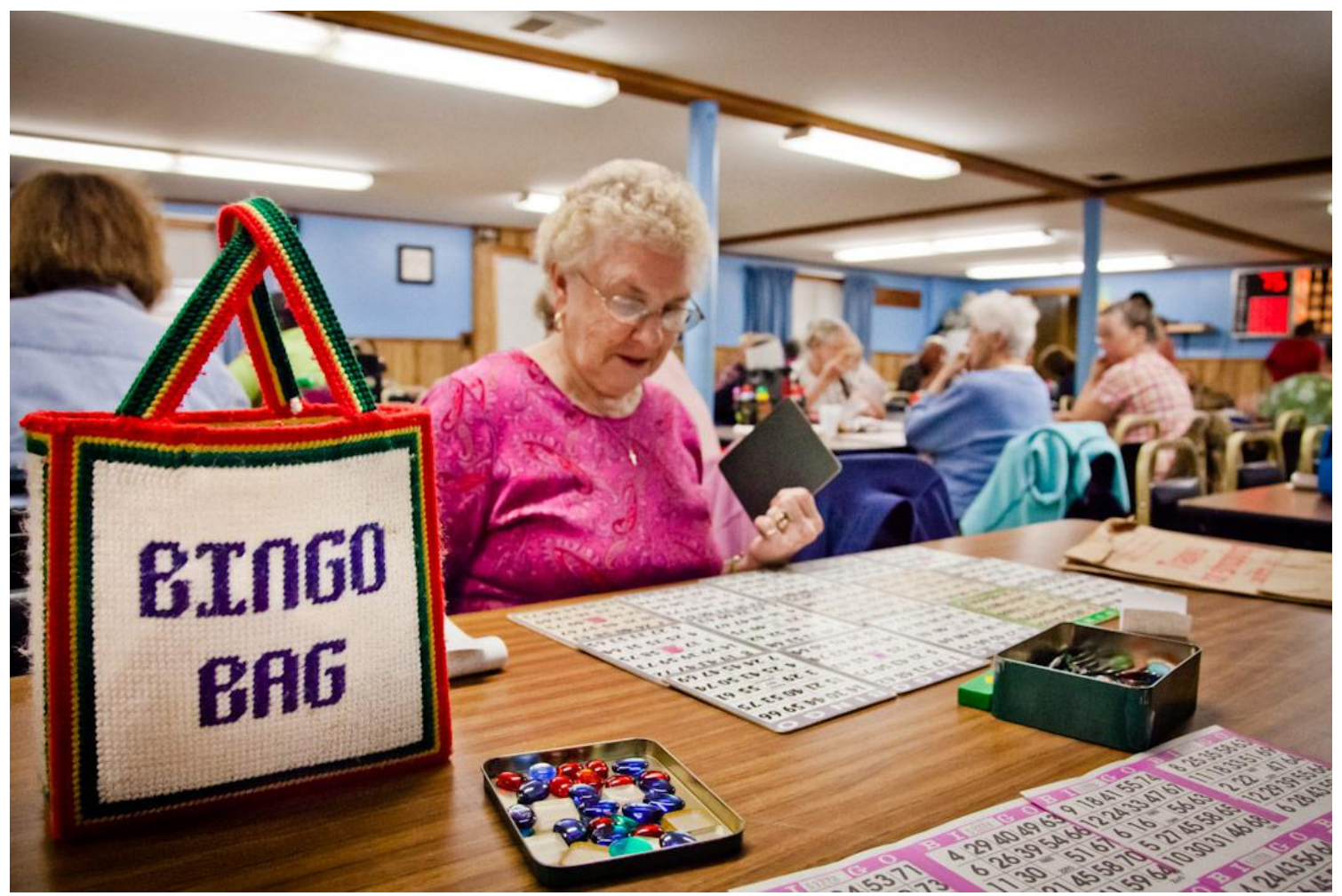

Photo by Alison Turner

Almost unanimously, when interviewees from the UK's licensed bingo sector were asked about problem gambling, they said that it was rare, and mostly concerned gambling machines. Generally, staff tended to be cautious about intervening, because they feared offending customers. However, they did intervene, often because they genuinely cared about helping people to get better, and sometimes, also, because the distress manifest was upsetting other customers, and/or causing complaints from family members. In the past, before SR had become a regulatory priority in the UK, informal but regularized mechanisms included 'having a chat'; telling someone to go home or to only come in with family or friends; refusing to serve alcohol to someone with a gambling problem; and 'letting someone know you are keeping an eye'. Staff also used measures equivalent to 'imposed self-exclusion' (where players with problems are identified by staff and barred) and 'third party self-exclusion' (where family members request that a player be barred and cut off from marketing). ${ }^{6}$

\footnotetext{
${ }^{6}$ Within gambling studies, such measures are considered to be at the extreme end of interventions designed to protect adults from themselves; see Reith and Scottish Centre for Social Research (ScotCen) 2006: 71; Hancock 2011: 149, 226.
} 
The reliance on informal measures that gave hall managers considerable discretion to design solutions in negotiation with players and their families has now given way to formal procedures mandated by legally binding codes. Since the 2005 Gambling Act came into effect in the UK, in September 2007, SR has become a key regulatory priority impacting the gambling industry as a whole. ${ }^{7}$ The same approaches to SR are being rolled out across different gambling sectors, and practices are increasingly standardized.

Moreover, the growing regulatory concern with SR has led to efforts to track players at an individual and aggregate level, via new technologies. In 2014, the national regulator, the Gambling Commission, launched a research initiative using loyalty card and anonymous transactional machine data, to see if there were technology driven measures that could minimize harmful play without impacting on those who do not exhibit harmful behaviours (see Department for Culture, Media and Sport 2014, and discussion in Miers 2015). The government also placed a requirement on larger betting shop operators to offer account based play. The move was welcomed by many observers, including some academics. The Responsible Gambling Trust funded further research into the topic (Forrest \& McHale, 2016).

In turn, cashless play is now being recommended in all sectors by the Gambling Commission, as part of the joint state and researcher faith that algorithms can access truths about gambling much more accurately than people can. Specifically, 'anonymous play' (with cash) is now framed as a SR problem, in part because it makes sector-wide self-exclusion policies harder to implement. In 2015, a Commission document announcing stricter SR codes for licensees opened with a foreword from organization's then-chair, Philip Graf, which laid out the case against cash on money laundering and harm prevention grounds:

"the anonymity currently inherent in cash-based gambling makes identifying and reducing harm much more challenging than it otherwise might be. It hampers research into the causes of harm and cost effective ways of mitigating it. And it makes more advanced player protection measures, such as feedback from patterns of play over time and associated operator action, virtually impossible to introduce effectively. It is also important to recognise that for some customers - those engaged in the disposal of criminal assets or fruits of the black economy - anonymity is highly attractive. Added to this, we are now in a world where new forms of harm reduction, based on data analytics, are becoming possible....Account-based or registered play - with the ability to link play to identified players over time-offers opportunities to identify those who potentially might be at risk of harm." (Gambling Commission 2015a: 3)

\footnotetext{
${ }^{7}$ I discuss the legislative, regulatory, and case law dimensions of this shift in some depth in the book.
} 
Although Graf noted opposition to player tracking, stemming from concerns about privacy and the personal freedom to dispose of funds that have been acquired legitimately, he stated that these are for Parliament, not the regulator, to address (2015, p. 4).

As a result, 'anonymous' (cash-based) play was identified as a problem to be managed, in part due to the faith that player tracking — at both the aggregate and individual level—will reduce harmful gambling and prevent money laundering. The gambling industry was warned that unless they voluntarily engaged with the regulator to address this problem, in the way proposed by the regulator (player-tracking), even stricter technological solutions may be imposed (Gambling Commission, 2015, p. 5). In 2018, GambleAware invited bids for a new research package on consumer vulnerability that is reliant on player tracking, and - in turn - on cashless play (Responsible Gambling Strategy Board, 2018). The Gambling Commission's current website guidance on Cashless payment technologies in gambling premises reiterates that new technologies for player tracking provide new opportunities for harm reduction.

\section{Paradox 1: Cash may be safer, and/or less anonymous.}

The first problem with this framing is that, broadly speaking, cash can be a useful technology for limiting spending in gambling: once it is gone it is not topped up. Conversely card use speeds up play and induces automaticity, in part by reducing interruptions. When cash money is turned into credit, it is more likely to get psychically separated off into a non-fungible form considered only viable for use in the exchange zone of the machine (Schüll, 2012, p. 56). This is perhaps why the casino sector has tried to encourage card use, or creation of credits, and why some problem gambling treatment providers recommend reliance on cash as a harm minimization measure. GambleAware's own leaflet 'Staying in control' advises:

Don't take your bank card with you. This is a good way to safeguard your money limit and not let being 'in the moment' warp your judgement.

Similarly, the Gambling Commission's webpage on cashless payments mentions research showing "that non-cash payment methods in gambling can lead to consumers over-spending, as such methods require less thinking about the actual cost and affordability implications of a transaction...compared to cash payments" (2019). Earlier this year, the Commission announced a ban on the use of credit cards for all forms of remote gambling, and for non-remote betting (the conditions for non-remote bingo and adult gaming centre licenses already prevented operators from accepting payments by credit card). This awareness of the risks of credit card use sits awkwardly with the enthusiasm for account-based play expressed by the same organizations.

Moving from gambling in general to bingo specifically, it becomes clear that in this sector cashusing players are not anonymous. In contrast, they may be well-known regulars. Their play may be opaque to data tracking systems, and central regulators, but it is easily legible within the hall, and staff are able to monitor it; they know precisely who is calling them over to change notes for coins to feed 
into side games, for example. In this regard staff hope that their cash-related interactions with bingo hall members can guide them as to whether people are experiencing problems. They have no such faith in player tracking technologies. Indeed, many interviewees were critical of moves to player tracking, given the low-risks associated with bingo, and the fact that its distinctive player demographic has a strong attachment to cash. As scholars exploring the demographics of the 'unbanked' have noted, cash is accessible for otherwise financially marginalized groups, ${ }^{8}$ including older people, women, and people on low incomes - precisely the demographic that dominates bingo. Indeed, many bingo players come with set amounts of cash for the session, leaving coins out for their side games or machine play for example. The idea that these are especially risky players, from a money laundering or problem gambling point of view, struck many in the bingo sector as absurd.

\section{Paradox 2: Online bingo becomes the model for social responsibility.}

Many land-based bingo staff in the UK point resentfully to the inverse relationship between the lower levels of harm caused by their products, and the freer rein given to online operators who are able to offer product mixes prohibited in brick and mortar halls (including card games such as poker, and online roulette). Moreover, online bingo is seen as more risky in part because players can easily lose track of spending. These concerns have made their way into political debate: for example, MPs have spoken in Westminster's Parliament of constituents who had struggled with online bingo addictions, criticizing the lack of spending limits, the difficulty of closing accounts, and the continued marketing directed at people who had tried to stop playing. ${ }^{9}$

Despite these concerns, due to the regulatory embrace of player tracking solutions to SR a paradox has emerged whereby online bingo — long seen as more risky than land-based play—is being (re)positioned as safe, because its technologies enable greater surveillance. Regulators and land-based bingo operators are at odds here, with the latter sometimes incredulous that the online sector is being seen to offer SR lessons. One land-based bingo expert insisted that underage players would 'last five minutes' if they tried to enter a hall, 'Coz somebody would spot them and they would be removed' (Interview A29), whereas with access to a payment card they could play online. Hence in a Q\&A session with the Gambling Commission at a 2015 bingo industry meeting, one irritated land-based operator challenged the regulator on the failure to control online play, stating 'The problem is online! Not the bricks and mortar.' The answer from the Commission was that 'Online is traceable. Every single transaction.' The fact that the online player is completely transparent — far more so than their land-based counterpart—is a 'very valuable asset for regulatory interventions' (fieldnotes). For online operators and regulators, traceability through centralized player tracking systems is key; for halls, what matters is other ways of 'seeing'.

\footnotetext{
${ }^{8}$ See e.g. Squires 2009: 22; Fung Huynh and Stuber 2015; Bagnall and Flood 2011.

${ }^{9}$ See Hansard reports including Jessica Morden in 574 Parl. Deb. HC (6th ser.) (30 January 2014) col. 1001; see also 492 Parl. Deb. HC (6th ser.) (13 May 2009) cols. 964-83.
} 


\section{Conclusion.}

Put bluntly, I agree with the hall managers that players are probably safer in halls, and that technologies being heralded as SR aids may make problematic gambling worse. The danger is that people will be ported into cashless, account based forms of play that purport to be safer, but that actually undermine existing mechanisms for regulating spending.

More broadly, however, these measures are of concern because they further entrench governmental and researcher faith in algorithmic approaches, and the online technologies of which they are a part, to resolve social problems. In this regard the promotion of cashless, account-based play reflects the broader capture of the regulator (and some gambling academics) by technological imaginaries about perfect surveillance via electronic payments. In this respect, the embrace of player tracking technologies within bingo offers a compelling example of the multiple investments being made in metadata.

In this, wider, sense, while I am concerned about measures being proposed to track bingo players because of what they mean for bingo players, I am also worried about the more general implications of the faith in algorithms to protect us from harm. That faith is not only misplaced, but also counterproductive. The power of algorithmic approaches is in part that they eclipse alternative regulatory solutions, and it is for this reason that the joint state/researcher interests in player tracking technologies need to be critically interrogated - because they may well lead to further exploitation, while problematizing the everyday behaviours of already marginalized, stigmatized groups of consumers. These approaches are also fundamentally opposed to the epistemological values that should inform qualitative approaches to gambling, such as the need for contextualized data, deep immersion in the field of enquiry, and listening carefully to people with most on-the-ground experience. In this respect the desire to port bingo players away from cash is important beyond bingo. Those with deep insider knowledge tell us that cash use helps regulate spending, and that online play is more harmful. But the embrace of data-driven solutions leads to regulatory recommendations for opposite approaches. At issue here is not just a way of playing bingo, but also an orientation to knowledge that links together the state, researchers, and dominant sectors of the gambling industry in new and potentially harmful ways. 


\section{References}

Andrejevic, M. (2012). 'Estranged Free Labor'. In Digital Labor, edited by Trebor Scholz, 150-64. New York: Routledge.

Bagnall, J., \& Flood, D. (2011). Cash Use in Australia: New Survey Evidence (pp. 55-62). Bulletin, September: Reserve Bank of Australia.

Bedford, K. (2015). Regulating Volunteers: Lessons from the Bingo Halls. Law and Social Inquiry, $40(2), 461-490$.

Bedford, K. (2018). Regulation and Resistance in Canadian Bingo: A Socio-Legal Account. Journal of Law and Social Policy, 30, 11-35.

Bedford, K. (2019). Bingo Capitalism: The Law and Political Economy of Everyday Gambling. Oxford: Oxford University Press, Law and Society series.

Bedford, K., \& Shieber, A. (2018b). Regulating Everyday Gambling: A Photo-essay.Feminists@law $8(1), 1-12$.

Boyd, D., \& Crawford, K. (2012). Critical questions for big data. Information, Communication \& Society, 15(5), 662-679.

Forrest, D., \& McHale, I. G. (2016). Tracked Play on B1 Gaming Machines in British Casinos. The Responsible Gambling Trust Machines Research Programme (June). Available here: https://about.gambleaware.org/media/1300/tracked-play-revision-26-6-16.pdf

Fung, B., Huynh, K. P., \& Stuber, G. (2015). 'The Use of Cash in Canada'. Bank of Canada Review, (spring), 45-56.

Gainsbury, S. (2011). Player account-based gambling: potentials for behaviour-based research methodologies. International Gambling Studies, 11(2), 153-171.

Gambling Commission (2015). Proposed Amendments to Licence Conditions and Codes of Practice for All Operators in Relation to the Prevention of Crime Associated with Gambling. Consultation (September). Department for Culture, Media and Sport. London: Stationery Office.

Gambling Commission (2019). Cashless payment technologies in gambling premises. Retrieved from https://www.gamblingcommission.gov.uk/for-gambling-businesses/Compliance/Generalcompliance/Social-responsibility/Cashless-payment-technologies.aspx. Last accessed November 2019.

Griffiths, M. (2014). The use of behavioural tracking methodologies in the study of online gambling. SAGE Research Methods Cases. doi:10.4135/978144627305013517480

Miers, D. (2015). Regulation and the management of risk in commercial gambling in Great Britain. International Gambling Studies, 15(3), 422-434.

Parke, J., Rigbye, J., \& Parke, A. (2008). Cashless and Card-Based Technologies in Gambling: A Review of the Literature. Salford: University of Salford. Available at: http://usir.salford.ac.uk/18206/1/Review_Cashless_Card_Technology_Gambling_Parke_2008.p df 
Reith, G. (2016). “Gambling 2": A Political Economy of Mobile and Social Gambling. Paper presented at the conference All Bets Are Off: Reflecting Critically on Gambling Regulation Within and Across Borders, University of Kent, Canterbury. 23 June.

Reith, G., \& the Scottish Centre for Social Research (ScotCen). (2006). Research on the Social Impacts of Gambling: Final Report. Edinburgh: Scottish Government.

Responsible Gambling Strategy Board (2018). Research Brief: Using industry data to understand patterns of play. Revised version. Available here: https://about.gambleaware.org/media/1749/3patterns-of-playfinalresearchbrief22062018rgsb.pdf

Rieder, G., \& Simon, J. (2016). Datatrust: Or, the political quest for numerical evidence and the epistemologies of Big Data. Big Data \& Society, 3(1), 1-6.

Scholz, T. (2012a). Digital Labor. New York: Routledge

Schüll, N. (2012). Addiction by Design: Machine Gambling in Las Vegas. Princeton: Princeton University Press.

Squires, G. (2009). 'Inequality and Access to Financial Services'. In Consumer Credit, Debt and Bankruptcy: Comparative and International Perspectivedited by Johanna Niemi, Iain Ramsay, and William C. Whitford, 11-30. Oxford: Hart.

The Bingo Project (2016). The Bingo Project: Final Report. Available at https://www.kent.ac.uk/thebingoproject/resources/Bingo_Project_report_final.pdf.

Van Dijck, J. (2014). Datafication, dataism and dataveillance: Big data between scientific paradigm and ideology. Surveillance \& Society 12(2), 197-208.

Yeung, K. (2017a). Algorithmic Regulation: A Critical Interrogation. Social Science Research Network SSRN Scholarly Paper ID 297250526 https://papers.ssrn.com/abstract=2972505.

Yeung, K. (2017b). "Hypernudge": Big data as a mode of regulation by design. Information, Communication \& Society, 20(1), 118-36. 